\title{
EDITORIAL
}

\section{A precarious position}

Another expert report on the US FDA has highlighted major deficiencies in the ability of the agency to meet current or emerging regulatory responsibilities. Action and the provision of sufficient resources to tackle these deficiencies should be a top priority.

In December 2006, the FDA Commissioner Andrew von Eschenbach requested that the agency's advisory board form a subcommittee to assess whether science and technology at the FDA can support future regulatory needs. A group of experts from industry, academia and other agencies has since been extensively investigating the issue, drawing on material from the FDA, previous reports on the agency and interviews with FDA staff and other key stakeholders. Their report was issued at the end of 2007 (REF. 1).

So, following a year that has clearly illustrated the extent of the challenges the FDA faces, with high-profile problems ranging from the cardiovascular risks of diabetes drugs to the safety of food imports, how well is the agency able to cope? On the basis of this report, the answer is a cause for considerable concern: “....science at the FDA is in a precarious position: the agency suffers from serious scientific deficiencies and is not positioned to meet current or emerging regulatory responsibilities"1.

The deficiencies are identified as stemming from two sources. First, demands on the FDA have increased dramatically. In the past two decades, the US Congress has enacted 125 statutes requiring some type of regulatory action, many of which involve the development of regulations or guidance, and need scientific expertise, and in some cases research, to be adequately addressed. Put in financial terms, the FDA now regulates $\sim$ US $\$ 1$ trillion in consumer products, with the Center for Drug Evaluation and Research (CDER) alone regulating \$275 billion in pharmaceutical sales, 2,500 US manufacturers and 2,500 foreign manufacturers. Furthermore, during this time, the rapid pace of scientific advances and the associated increase in the complexity of new products and the applications that the FDA reviews, the emergence of safety problems such as those with diabetes drugs, and globalization, have presented major new challenges to the agency.

Second, the resources of the FDA have not increased in proportion to the demands. In fact, in some respects, they have not increased at all: the appropriated budget $\$ 1.6$ billion in 2007 - has declined in real terms by $\sim 300$ million in the past 20 years, and without the oftencriticized user fees provided by the biopharma industry, the funding situation of the FDA would be even more dire. In addition, the number of appropriated personnel in 2007 was roughly the same as the number 15 years earlier, and very few employees are available to conduct the kind of research needed to put the agency in a strong position to drive the development of regulatory science. For example, the CDER has less than 100 lab-based scientists.

As the report notes, science is at the heart of the FDA's activities, and coupled together, the consequences of increased demands not matched by resources are that the agency cannot fulfil its mission of protecting and advancing public health for three reasons. First, its scientific base has eroded and its scientific organizational structure is weak ${ }^{1}$. Second, its scientific workforce does not have sufficient capacity and capability, in part owing to a failure to retain staff, and third, its information technology infrastructure is inadequate ${ }^{1}$.

These deficiencies have several serious implications for the future regulation of the biopharma industry. For example, the report found that the development of medical products based on 'new science' cannot be adequately regulated, although heroic efforts by several senior FDA administrators have resulted in a serious commitment to sustaining efforts in areas such as genomics that have been identified as a high priority in the FDA Critical Path Initiative $^{1,2}$. Nevertheless, many Critical Path projects that have been initiated are at risk, and none is adequately resourced $^{1}$, which is hardly surprising given that the CDER has just \$15 million per year in total for all research.

The report also provides a series of recommendations to tackle the issues identified, ranging from the development of new programmes to manage emerging science and technologies to instituting a new scientific organization. A major increase in resources is also urgently required, with the recommendation being an increase in appropriated funds to $\sim \$ 2.4$ billion in 2008 and to $\sim \$ 3.1$ billion in the following year. But perhaps the most significant note comes at the end ${ }^{1}$ : "There is a long history of excellent reviews of the FDA that have been followed by little to no action taken to achieve the recommendations." This time, this cannot be the case if the FDA is to become an agency well-positioned to fulfil its mission.

\footnotetext{
1. FDA Science and Mission at Risk [online], < http://www.fda.gov/ohrms/ dockets/ac/07/briefing/2007-4329b 0200 index.html > (2007).

2. Critical Path Opportunities List [online], < http://www.fda.gov/oc/ Critical Path Opportunities List [online], < http://WWW.
initiatives/criticalpath/reports/opp_list.pdf $>$ (2006).
} 